\title{
Etanercept-induced anti-Jo-1- antibody-positive polymyositis in a patient with rheumatoid arthritis: a case report and review of the literature.
}

\author{
$\operatorname{AUTHOR}(\mathrm{S})$ : \\ Ishikawa, Yuki; Yukawa, Naoichiro; Ohmura, Koichiro; \\ Hosono, Yuji; Imura, Yoshitaka; Kawabata, Daisuke; Nojima, \\ Takaki; Fujii, Takao; Usui, Takashi; Mimori, Tsuneyo
}

\section{CITATION:}

Ishikawa, Yuki ... [et al]. Etanercept-induced anti-Jo-1-antibody-positive polymyositis in a patient with rheumatoid arthritis: a case report and review of the literature.. Clinical rheumatology 2010, 29(5): 563-566

\section{ISSUE DATE:}

2010-05

URL:

http://hdl.handle.net/2433/120949

\section{RIGHT:}

The original publication is available at www.springerlink.com; This is not the published version. Please cite only the published version.; この 論文は出版社版でありません。引用の際には出版社版をご確認ご利用 ください。 


\begin{tabular}{|c|c|c|c|c|c|}
\hline Case [Reference number] & Patient 1[11] & Patient 2[12] & Patient $3[13]$ & Patient 4[14] & Present case \\
\hline Age(yrs) \& Sex & 44 female & 52 female & 52 female & 57 female & 58 female \\
\hline $\mathrm{RF} / \mathrm{CCP}$ & $-/-$ & $+/ \mathrm{ND}^{* 1}$ & $+/ \mathrm{ND}$ & $+/ \mathrm{ND}$ & $+(724.7) /+(>100)$ \\
\hline $\begin{array}{c}\text { Duration from RA until anti-TNF } \\
\text { therapy }(T x .) \text { initiation (yrs) }\end{array}$ & 1 & 20 & 33 & 26 & 2 \\
\hline Previous Tx. for RA & $\mathrm{HCQ}^{* 2}, \mathrm{MTX}^{* 3}$ & MTX & MTX & All available DMARDs & BUC ${ }^{*}$, TAC $^{* 5}$ \\
\hline Anti-TNF therapy & Etanercept & Infliximab & Infliximab & Etanercept & Etanercept \\
\hline $\begin{array}{l}\text { PM/DM onset from anti-TNF Tx. } \\
\text { initiation }\end{array}$ & 6 months & 6 months & 9 months & 6 wks after re-treatment & 2 months \\
\hline Maximum $\mathrm{CK}^{* 6}(\mathrm{IU} / \mathrm{L})$ & 11,593 & $>12,000$ & 3,388 & 1,067 & 1,538 \\
\hline pre FANA & - & $1: 320$, pattern unknown & $1: 640, \mathrm{Ho}^{* 7} / \mathrm{Spe}^{* 8}$ & $1: 160$ (1999) & 1:320, Ho./Nuc. ${ }^{* 9}$ \\
\hline Pre ${ }^{* 10}$ anti-dsDNA antibody & ND & - & - & ND & - \\
\hline Anti-dsDNA antibody & ND & $1: 20$ & $\operatorname{IgM}(131 \mathrm{U} / \mathrm{mL})$ & ND & $-(\operatorname{IgG} 11 \mathrm{U} / \mathrm{mL})$ \\
\hline Pre Anti-Jo-1 antibody & ND & + & $+(>500 \mathrm{U} / \mathrm{mL})(\mathrm{ELISA})$ & ND & 206.9 \\
\hline Anti-Jo-1 antibody & + & + & $+(>500 \mathrm{U} / \mathrm{mL})(\mathrm{ELISA})$ & ND & 239 \\
\hline Electromyogram & ND & ND & ND & Myogenic pattern & Myogenic pattern \\
\hline Muscle biopsy & $\begin{array}{l}\text { Necrosis, perivascular } \\
\text { interstitial infiltration }\end{array}$ & $\begin{array}{l}\text { Diffuse necrosis, } \\
\text { inflammatory infiltrates }\end{array}$ & $\begin{array}{l}\text { Size variation, inflammatory } \\
\text { infiltrates }\end{array}$ & Necrotizing myositis & $\begin{array}{c}\text { Mild inflammtory infiltrates } \\
\text { and necrosis }\end{array}$ \\
\hline Diagnosis & Dermatomyositis & Polymyositis & Polymyositis & Polymyositis & Polymyositis \\
\hline Course \& types of ILD & Improved; NSIP ${ }^{* 11} ?$ & Improved; UIP ${ }^{* 12} ?$ & Improved; NSIP ? & ARDS developed, due to $\mathrm{PCP}{ }^{* 13} ?$ & Improved; NSIP or BOOP ${ }^{* 14}$ \\
\hline Tx. for PM/DM※15 & $\begin{array}{l}\text { High-dose PSL }{ }^{* 16} \text { plus AZP }{ }^{\star} \\
17150 \mathrm{mg} \& \text { MTX } 10 \mathrm{mg} / \mathrm{wk}\end{array}$ & $\begin{array}{c}\text { MP }{ }^{* 18} \text { pulse } 1.0 \text { g plus } P S L \\
1 \mathrm{mg} / \mathrm{kg}\end{array}$ & PSL 30 mg plus TAC 3 mg & $\begin{array}{l}\text { High-dose PSL plus IVCY }{ }^{* 19}(500 \\
\left.\mathrm{mg} / \mathrm{m}^{2}\right)\end{array}$ & $\begin{array}{c}\text { PSL } 1 \mathrm{mg} / \mathrm{kg} \text { plus MP pulse } \\
0.5 \mathrm{~g}\end{array}$ \\
\hline Outcome of myositis & Marked improvement & Marked improvement & Marked improvement & Marked improvement & Marked improvement \\
\hline
\end{tabular}

Table 1. Clinical Characteristics of Reported RA Patients Who Developed PM/DM After Anti-TNF Therapy

$※ 1$ ND Not done or Not described $* 2 \mathrm{HCQ} * 3 \mathrm{MTX}$ methotrexate hydroxychloropuine $* 4$ BUC bucillamine $* 5$

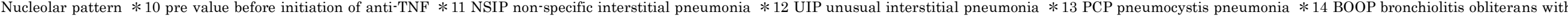
organizing pneumonia $* 15$ All treatment include withdrawl of anti-TNF therapy $* 16$ PSL prednisolone $* 17$ AZP azathioprine $* 18$ MP methylprednisolone $* 19$ IVCY intravenous cyclophosphamide 